A model of a rotary film evaporator with a film-forming element with a reflective heated surface has been developed. This will allow stabilizing the hydraulic movement of the cut wave flow due to the reflective surface of the geometric shape for the forced direction of the cut raw material to the heating surface. Autonomous heating of the reflective surface additionally provides a temperature effect in the conditions of movement of particles of raw materials after cutting.

The analysis of the experimental and theoretical parameters of heat transfer made it possible to substantiate the criterion equation for determining the heat transfer coefficient of an evaporator with the proposed film-forming element and a reflective heated surface for calculating the coefficient from the working surface to the raw material. The resulting equation takes into account the influence of the vertical component of the motion of the raw material film, centrifugal movement during the rotation of the film-forming element, mixing of the boiling film of the raw material with steam bubbles, and the geometric characteristics of the film-forming blade on the hydrodynamic flow of the raw material. The calculation of the rotary-film evaporator was carried out using the criterion equation and the obtained useful heat exchange surface $-0.75 \mathrm{~m}^{2}$. The specific metal consumption in a rotary film evaporator with a film-forming element having a reflective surface is $57 \mathrm{~kg} / \mathrm{m}^{2}$, compared to the vacuum evaporator traditionally used in canning industries $\left(410 \mathrm{~kg} / \mathrm{m}^{2}\right)$, which is 7.1 times less. The duration of the temperature effect on the raw material is also reduced: a rotary film evaporator $200 s$ and $3600 s$ in a traditional apparatus. The data obtained will be useful for the design of rotary-film devices of different geometric parameters using articulated blades with a reflective plate

Keywords: heat transfer coefficient, rotary film evaporator, criterion equation, film-forming element, organic raw materials

\title{
DETERMINATION OF THE HEAT TRANSFER COEFFICIENT OF A ROTARY FILM EVAPORATOR WITH A HEATING FILM- FORMING ELEMENT
}

\author{
Andrii Zahorulko \\ Corresponding author \\ $\mathrm{PhD}$, Associate Professor* \\ E-mail: zagorulkoAN@hduht.edu.ua \\ Aleksey Zagorulko \\ $\mathrm{PhD}$, Associate Professor* \\ O leksander Cherevko \\ Doctor of Technical Sciences, Professor \\ Department of Processes and Equipment Food \\ and Hospitality-Restaurant Industry named after M. Belaev \\ Kharkiv State University of Food Technology and Trade \\ Klochkivska str., 333, Kharkiv, Ukraine, 61051 \\ O Iena Dromenko \\ $\mathrm{PhD}$, Associate Professor \\ Department of Meat Technology** \\ Alla Solomon \\ $\mathrm{PhD}$, Associate Professor \\ Department of Food Technologies and Microbiology \\ Vinnytsia National Agrarian University \\ Sonyachna str., 3. Vinnytsia, Ukraine, 21008 \\ Roman Yakobchuk \\ $\mathrm{PhD}$, Associate Professor \\ National University of Food Technologies \\ Volodymyrska str., 68, Kyiv, Ukraine, 01601 \\ Oksana Bondarenko \\ $\mathrm{PhD} * * *$ \\ Natalia Nozdrina \\ $\mathrm{PhD} * * *$ \\ *Department of Equipment and Engineering of Processing \\ and Food Production** \\ ** State Biotechnological University \\ Alchevskykh str., 44, Kharkiv, Ukraine, 61002 \\ $* * *$ Department of Plant Production \\ Dnipro State Agrarian and Economic University \\ Serhiya Yefremova str., 25, Dnipro, Ukraine, 49600
}

Department of Technological Equipment and Computer Technology Design

Received date 22.10.2021 Accepted date 02.12.2021 Published date 24.12.2021
How to Cite: Zahorulko, A., Zagorulko, A., Cherevko, O., Dromenko, O., Solomon, A., Yakobchuk, R., Bondarenko, O., Nozdrina, N. (2021). Determination of the heat transfer coefficient of a rotary film evaporator with a heating film-forming element. Eastern-European Journal of Enterprise Technologies, 6 (8 (114)), 41-47. doi: https://doi.org/10.15587/1729-4061.2021.247283
1. Introduction

In many areas of the processing and food industries, in the implementation of technological operations in the production of various products, heat and mass transfer operations are used (heating, holding, boiling, etc.). The combination of thermal operations in a single complex of heat and mass transfer equipment makes it possible to significantly 
intensify the hardware and technological complex as a whole due to resource efficiency, to reduce the duration of processes and the quality of the resulting products [1]. When developing modern complexes, the main attention is paid to the introduction of innovative engineering and technological solutions using mathematical modeling and forecasting of the provision of effective hardware and technological properties, depending on the input and output parameters.

In connection with environmental and pandemic challenges, the issue of production of functional and physiological ingredients of a high degree of readiness and health-improving and prophylactic products of high quality of organic plant origin is acute today [2]. Since this raw material is a natural source of biologically active substances, micro- and microelements, dyes and original organoleptic properties, which will minimize the use of synthetic impurities in technological operations. Therefore, to receive high-quality food products with increased nutritional value, therapeutic and prophylactic properties for the formation of a rational nutritional system, thereby forming the immune component and strengthening health in general [3].

Providing resource efficiency of heat and mass transfer operations is possible with the use of modern innovative solutions, including complexes for processing secondary energy when processing organic raw materials. When designing thermal equipment, it is important to carry out constructive calculations to establish the rational geometric dimensions of the apparatus and working bodies, which, in general, will ensure the resource efficiency of the heat and mass transfer process. The quality of the implementation of the concentration process and the resulting final values of the heat and mass transfer calculation (heat exchange surface, the amount of consumed heat, etc.) depend on the completeness of taking into account the design and technological parameters in the criterion equation. Consequently, the introduction in the development of modern evaporators of the rotary-film type and an adequate design model for determining the heat transfer coefficient will not only make it possible to determine the main design parameters of the equipment.

For the implementation of resource-efficient heat and mass transfer processes of concentration, an urgent task is to ensure the quality of the products obtained through the use of modern engineering and technological solutions in the context of reducing the duration of technological operations. One of such solutions is the substantiation of the criterion equation for determining the heat transfer coefficient of rotary film evaporators, which will allow obtaining the calculated values with the maximum reliability of describing the real picture of the heat and mass transfer process. The calculated data obtained will make it possible to ensure the optimal geometric dimensions of the apparatus when designing new rotary evaporative equipment, taking into account all the factors influencing the process in order to achieve their resource efficiency. The introduction of optimal modeling and forecasting of rational heat and mass transfer operations, including for increasing the heat transfer coefficient, will ensure the production of high-quality products while ensuring their competitiveness.

\section{Literature review and problem statement}

The work [4] provides marketing research on the relevance of the implementation of efficient processing of raw materials based on a variety of technological processes to obtain high-quality competitive food products. This is due to the fact that, in comparison with traditional analogs, improved methods provide better resource efficiency, due to a decrease in metal consumption, a reduction in technological and operational duration, the use of secondary heat energy, etc. However, issues related to state support for investment programs for formatting obsolete complexes, technologies, etc. remain unresolved. This is primarily due to the fact that most of the hardware systems are characterized by energy and metal consumption and are even difficult to improve, necessitating the search for innovative technical solutions to support the domestic industry. Thus, the work [5] indicates the need to improve the quality of various products due to constant hardware and technological re-equipment to increase resource efficiency and allows taking into account the initial and final properties of the processed raw materials.

In particular, in [6], a model was developed for determining the relationship of energy costs when concentrating non-Newtonian liquids under conditions of heating the working surface with a steam jacket. However, the neglected operational and technical complexity of the process, which leads to a decrease in resource efficiency, and therefore the proposed model is based on the consideration of individual indicators, and not the process as a whole, requiring further research. The work [7] investigates an improved model design of a film evaporator for analytical prediction of heat and mass transfer processes of concentration, taking into account the hydrodynamic and thermophysical design and technological features of the implementation of the processes. But the remaining issues of the formation of generalizing recommendatory parameters to ensure the guaranteed quality of the obtained semi-finished products of a high degree of readiness, taking into account the method of heat supply, have not been resolved. One of the solutions is given in [8] and is based on the concentration of pomegranate juice with an initial content of $13 \%$ dry matter using ohmic heating. As a result of the research, the influence on the heat transfer coefficient of the relationship between heating, the energy expended on the boiling down of natural raw materials and the area of the cutting surface in conditions of an increase in the content of dry substances was determined. Nevertheless, questions related to the need to stabilize the trajectory of motion of a wavy film flow after cutting with an edge remain unattended. This is due to the complexity of approbation of the rational geometric surface of the pressure plate in the conditions of using hydrodynamic modeling, and therefore focuses on the expediency of research in this direction. One of the practical solutions is given in [9] when improving a rotary film evaporator with a shearing blade for concentrating vegetable purees. But the work did not pay attention to the ways of increasing the efficiency of the process in the conditions of modeling the criterion equation for determining and predicting the heat transfer coefficient, which necessitated further research.

The use of the proposed shear blade with a reflective surface leads to an increase in the heat transfer coefficient by about $20 \%$ compared to the basic design of a rectangular blade. The obtained calculated data on the specific energy consumption of heating a unit volume of the product in the $\mathrm{RFE}$ is $408 \mathrm{~kJ} / \mathrm{kg}$ compared to the basic vacuum evaporator - $1019 \mathrm{~kJ} / \mathrm{kg}$, which characterizes a decrease in costs by 1.97 times. At the same time, the duration of heat treatment in the RFE is $60 \mathrm{~s}$, and in the base VEA $1 \mathrm{~h}$, which shows a significant decrease in the temperature effect on the raw material. The data obtained testify to the effectiveness of constructive and technical solutions. The engineering and 
technological component of any heat and mass transfer processes, in particular the concentration of fruit and berry raw materials, is the main one in the production of food semi-finished products of a high degree of readiness. It should also take into account the efficiency of using methods for the production of vegetable pasty semi-finished products of a high degree of readiness for further use in various food products [10]. Thus, in the production of culinary meat products in the developed low-temperature installation, vegetable components are added to the meat product to increase the nutritional value and impart original taste properties [11].

In [7], the process of heat transfer of a non-Newtonian pseudoplastic fluid inside a scraped surface heat exchanger was analyzed under conditions of contact of the rod with semicircular parts installed on it with the inner surface of the pipe. With such a constructive solution, the authors achieved an increase in heat transfer under the conditions of measuring the pressure drop, heat transfer and consumed energy when boiling non-Newtonian liquids under static and dynamic conditions of the scraper for four flow regions. The results obtained prove the possibility of using the apparatus in industry, even in conditions of increased power consumption for the rotary motion of the scraper, however, the actions of the authors are based on the achievement of technological needs, neglecting resource efficiency. This is due to the fact that, unfortunately, there is a need in industry to ensure that, first of all, technological needs are achieved. One of the solutions is given in [12] in the analysis of Eyring-Powell fluids in scraped surface heat exchangers, indicating that food products have non-Newtonian properties. The authors determined the hydrodynamic behavior of non-Newtonian fluids in a scraped surface heat exchanger using rotating scraper blades, which made it possible to obtain velocity profiles. However, the work does not provide data on the method of heat supply during concentration and the effect of introducing a reflective surface into the structure of the film-forming element (scraper) to stabilize the hydrodynamic flow. And in work [13] isometric fields of the wavelike flow of the suspension were determined under the conditions of determining the vortex flow from the blades due to the lack of research on obtaining the uniformity of the distribution of raw materials after cutting. This may be due to the complexity of modeling the above-mentioned parameters that were not taken into account, however, their technical implementation will increase the heat transfer coefficient, especially when providing a heated reflective surface of the shearing blade. Thereby, causing further research in this direction.

In [14], a hydrodynamic model is presented that takes into account the change in the Reynolds and Nusselt numbers when concentrating plant raw materials for further determination of the heat transfer coefficient in a scraped surface heat exchanger. However, the work does not take into account the geometric shape of the film-forming elements, which greatly complicates the further testing of the results obtained. One of the solutions is given in [15] by modeling the hydrodynamic flow of raw materials based on previously formed theoretically literary data and subsequent additions with experimentally obtained ones. As a result of the research, the influence on the heat transfer coefficient of the properties of raw materials, the design features of the cutting blade and the properties of the heating surface was established, focusing on the feasibility of scientific and practical research in this direction.
The existing technical equipment of the processing industry in many countries is implemented using traditional heat and mass transfer equipment: digesters, vacuum evaporators, heaters, rotary evaporators, etc., which in most cases have low resource efficiency [16]. This is due to the high energy and metal consumption when using steam jackets, various intermediate heat carriers, etc., as well as the complexity of the hardware improvement. There are also difficulties in ensuring high values of the heat supply coefficient, taking into account the geometric properties of the film-forming elements, methods of heat supply and stabilization of the wave flow after cutting. Therefore, it is advisable to conduct a study devoted to the scientific and practical substantiation of criterion equations for determining the indicator of the effective heat transfer coefficient, taking into account the proposed working surfaces of the evaporator when using heating film-forming elements. This, in turn, will provide an increase in the resource efficiency of rotary film evaporators in conditions of rational concentration of food raw materials with predicted hydrodynamic movement, depending on the design features of the blades. Consequently, it will ensure the high quality of the products obtained and the competitiveness of the hardware and technological complex as a whole, the expediency of research in this direction.

\section{The aim and objectives of research}

The aim of research is to theoretically and practically substantiate the selection of a criterion equation for determining the heat transfer coefficient from the working surface of a rotary film evaporator with a heating film-forming element to the raw material processed to form the optimal geometric parameters of the working surface. This will make it possible to effectively determine the heat and mass transfer properties of concentration processes in conditions of an increase in the heat transfer coefficient.

To achieve the set aim, the following objectives were solved:

- to improve the design of the film-forming element of the rotary-film evaporator by heating the reflecting surface due to the flexible film resistive electric heater of the emitting type;

- to substantiate the criterion equation for determining the heat transfer coefficient from the working surface of a rotary film evaporator with a heating film-forming element to the raw material.

\section{Materials and methods of research}

Experimental and practical research was carried out on the basis of the Research Center "New biotechnologies and equipment for the production of food products with high health-improving properties" State Biotechnological University (Ukraine).

When forming the criterion equation, the traditional criteria of Nusselt, Reynolds centrifugal, Prandtl were used. As well as clarifying indicators responsible for heat transfer during gravitational runoff of the film, its boiling and the geometric properties of a film-forming element with a reflective surface. The wave flow velocity and the resulting film thickness were determined from the Nusselt equation, while the experimental data were processed using the MathCat package (United States of America). 


\section{Results of experimental and computational studies of the improved rotary film evaporator}

5. 1. To improve the design of a film-forming element with a heated reflective surface of a rotary film evaporator

The quality of heat and mass transfer operations, such as concentration, heating, etc. with the use of rotary film evaporators in most cases depends on the method of heat supply, the design of the film-forming element, and the stabilization of the hydraulic wave flow. In particular, the stabilization of the film-like flow at the moment of draining and after shearing off the film-forming element by the edge affects the final heat transfer coefficient. Traditional designs of rotary film evaporators are characterized by a variety of geometrical designs of sludge-forming elements (hinged, rectangular, etc.), which provide, to a certain extent, effective indicators of cutting and mixing of experimental raw materials. These designs are intended for cutting off the film formed on the working surface, which, after cutting, partially hangs in the working space of the apparatus and only then falls on the heating surface due to the effect of centrifugal speed. One of the solutions for stabilizing the hydraulic motion of the cut wave flow is the use of a reflective surface of a certain geometric shape, which will allow forcibly directing the cut raw material to the heating surface. In addition, an important factor, in addition to stabilizing the wave motion, is to provide heating of the reflecting surface area for an additional temperature effect under conditions of movement of raw material particles after cutting.

To implement the scientific and practical testing of the proposed engineering solutions aimed at improving the design of the film-forming element of the rotary-film evaporator by heating the reflective surface using a flexible film resistive radiating electric heater (FFRREH) [17]. A schematic diagram of the experimental research model of a rotary film evaporator is shown in Fig. 1, $a$. The improved design of a film-forming element with a heated reflective surface, shown in Fig. 1, $b$, and the hydraulic flow stabilization scheme is shown in Fig. 1, $c$.

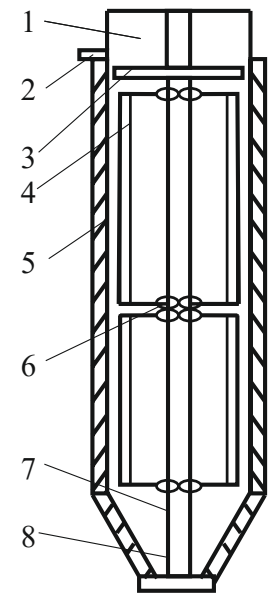

a

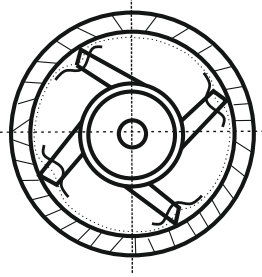

$b$

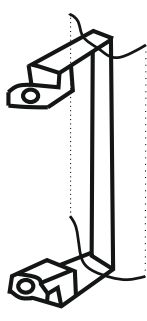

c
Fig. 1. Diagram of the experimental research model of the rotary film evaporator: $a, b$ - longitudinal and cross sections of the apparatus; $c$ - the design of the film-forming element with a heated reflective surface; 1 - section of separation of vapor-containing medium; $2-$ a branch pipe for injection of experimental raw materials; 3 - distribution disk; 4 - an improved film-forming element with a heated reflective surface; 5 - flexible film resistive radiating electric heater (FFRREH); 6 - hinged clamps of the film-forming element; 7 - rotary shaft; 8 - apparatus unloading department
The model design of the rotary film evaporator works as follows: the experimental puree-like raw material is pumped through the branch pipe 2 and enters the distribution disk, designed to form a film with its subsequent outflow by the working surface of the apparatus. Heated by FFRREH, which allows to eliminate the steam jacket of traditional rotary-film apparatus, and therefore to increase the efficiency of the process as a whole. After the film is formed by the distributor disk 3 , it is picked up by the improved film-forming elements with the heated reflective surface 4 . Thereby, the film is cut off by the film-forming element and forced onto the heating surface due to the geometric shape of the reflective surface. And also due to the autonomous heating of the reflective surface based on FFRREH, the temperature of stabilization of the mixed raw material after cutting by the film-forming element is provided. The film-forming elements are attached to the rotary shaft 7 by means of hinged clamps 6 . The autonomy of the FFRREH of the reflecting surface is ensured by converting thermal energy by the Peltier elements placed in the separating space into a low-voltage power supply, which is sufficient for heating electric heating. After passing through the working space, the concentrated raw material enters the unloading department and is removed from the apparatus.

5. 2. Substantiation of the criterion equation for determining the heat transfer coefficient of a rotary film evaporator

To ensure high-quality concentration of puree plant raw materials in rotary film evaporators with an improved heating film-forming element, it is necessary to obtain a criterion equation that will take into account the effect on itself before the generalized parameters of heat and mass transfer. In particular, the heat transfer coefficient is determined by the nature of the motion and the dependence of the initial and obtained in the process of concentration thermophysical properties of the experimental raw material. In this case, convective heat transfer takes into account the quantitative parameter of the Prandtl value (Pr), modified by Reynolds (Re) under boiling conditions with the formation of bubbles, depending on the heating surfaces and Grashof (Gr) under free and forced convection. And taking into account the geometric properties of the improved film-forming element, the criterion equation will have the following generalized form:

$$
N u=A \operatorname{R} c^{n_{1}} \mathrm{Gr}^{n_{2}} \operatorname{Re}_{\text {boil }}^{n_{3}} \operatorname{Pr}^{n_{4}} .
$$

Taking into account the vertical placement of the working chamber of the apparatus under conditions of gravitational film-like motion of experimental raw materials, in particular, runoff and centrifugal movement due to the edge and reflective blade of the blade in conditions of vaporization. It determines the use of three numerical Reynolds parameters when taking into account the three speeds of movement of raw materials: axial, circumferential and boiling, as well as the centrifugal Grashof criterion. In this case, the Grashof gravitational criterion can be neglected, since the film flow is complicated by thermal convection, so that the Grashof centrifugal number will look like this: 


$$
\mathrm{Gr}_{c}=\beta \omega^{2} \mathrm{Rl}^{3} \Delta T / \mathrm{v}^{2}
$$

When cutting a mobile film-like flow of raw materials by the edge of the blade, the wave nature of the cut surface is formed and significantly affects the nature of the hydraulic movement of the film. During approbation, we used the initial data of the experimental raw materials and the model design of the rotary film evaporator with the following parameters: diameter $-D=0.035 \mathrm{~m}$; raw material consumption $-G=1 \cdot 4 \cdot 10^{-3} \mathrm{~kg} / \mathrm{s}$. Specific heat of vaporization $r=2.35 \cdot 10^{6} \mathrm{~J} / \mathrm{kg}$, heat flux density $-q=1.44 \cdot 10^{4} \mathrm{~W} / \mathrm{m}^{2}$ and experimental raw material $-\rho=1200 \mathrm{~Pa}$ s, Prandtl number $\operatorname{Pr}=1.84 \cdot 10^{4}$ and rotation frequency rotor $n=1.16 \mathrm{~s}^{-1}$.

The density of the coalescence of the working rotor-film surface will be determined by the equation:

$$
\mathrm{Gr}=G / \pi \cdot D=1.4 \cdot 10^{-3} / 3.14 \cdot 3.5 \cdot 10^{-2}=1,27 \cdot 10^{-2} \mathrm{~kg} / \mathrm{s} \cdot \mathrm{m} .
$$

The Reynolds number for the axial velocity of the test liquid in a rotary film evaporator is characterized by the equation:

$$
\mathrm{Re}=\mathrm{Gr} / \mathrm{\eta}=1.27 \cdot 10^{-2} / 2.5=5.1 \cdot 10^{-3} .
$$

The obtained numerical parameter of the Reynolds number makes it possible to use the numerical results of Nusselt to solve the problem under conditions of gravitational runoff of a film-like flow, neglecting the inertial forces, so that the film thickness according to Nusselt will be calculated as follows

$$
\delta=\sqrt[3]{\frac{3 G r \eta}{\rho^{2} g}}=\sqrt[3]{\frac{3 \cdot 1.27 \cdot 10^{-2} \cdot 2.5}{1.2^{2} \cdot 10^{6} \cdot 9.81}}=1.9 \cdot 10^{-3} \mathrm{~m}
$$

therefore, the rate of vertical runoff of film-like raw materials in a rotary film evaporator will be determined by the following equation:

$$
v_{f}=\frac{G r}{\rho \delta}=\frac{1.27 \cdot 10^{-2}}{1,200 \cdot 1.9 \cdot 10^{-3}}=5.57 \cdot 10^{-3} \mathrm{~m} / \mathrm{s}
$$

The criterion Reynolds equation along a spiral trajectory of motion (rotating) speed, taking into account that $\mathrm{v}_{r}=\pi D$ $n=3.14 \cdot 0.035 \cdot 1.16=0.127 \mathrm{~m} / \mathrm{s}$, then it will be described by the equation:

$$
\operatorname{Re}_{c}=\rho v \delta / \eta=1.200 \cdot 0.127 \cdot 1.9 \cdot 10^{-3} / 2.5,
$$

To calculate the values of the evaporated moisture from the experimental raw materials, namely, the vapor density, the coefficient of volumetric expansion and surface tension, let's invert the values of water in a state of saturation at $100{ }^{\circ} \mathrm{C}: \rho_{n}=5.97 \cdot 10^{-1} \mathrm{~kg} / \mathrm{m}^{3} ; \beta=7.15 \cdot 10^{-4} 1 / \mathrm{K}$ and $\sigma=5.89 \cdot 10^{-2} \mathrm{~N} / \mathrm{m}$.

$$
\begin{aligned}
& \delta_{k}=\sqrt{\frac{\sigma}{g\left(\rho-\rho_{i}\right)}}= \\
& =\sqrt{\frac{5.89 \cdot 10^{-2}}{9.81\left(1.2 \cdot 10^{3}-5.97 \cdot 10^{-1}\right)}}=2.238 \cdot 10^{-3} \mathrm{~m}, \\
& v_{\text {boil }}=\frac{q}{r \rho_{n}}=\frac{1.44 \cdot 10^{4}}{2.35 \cdot 10^{6} \cdot 5.97 \cdot 10^{-1}}=10.26 \cdot 10^{-3} \mathrm{~m} / \mathrm{s},
\end{aligned}
$$

$$
\begin{aligned}
& \mathrm{Gr}_{c}=\frac{\beta \omega^{2} R l^{3} \Delta T}{v^{2}}= \\
& =\frac{7.15 \cdot 10^{-4}(2 \cdot 3.14 \cdot 1.16)^{2} 3.5 \cdot 10^{-2}\left(1.88 \cdot 10^{-3}\right) \cdot 5}{(2.5 / 1200)}= \\
& =0.67 \cdot 10^{-4} .
\end{aligned}
$$

In this case, the indicators of thickness and speed $\left(\delta_{k}, \mathrm{v}_{k}\right)$ are commensurate with $\delta=1.88 \cdot 10^{-3} \mathrm{~m}$ and $\mathrm{v}_{\mathrm{film}}=5.58 \cdot 10^{-3} \mathrm{~m} / \mathrm{s}$, so that the obtained equations are characterized by the properties of the raw material layer in the form of the linear size of the process boiling. The $v_{k}$ index characterizes and indicates the uniformity of the effect on the heat exchange of the boiling process and the gravitational movement of the experimental raw material. At the same time, the high viscosity of the raw material leads to the minimum Grashof number, therefore, the expression: $\mathrm{GrPr}$ is characterized by the value of the absence of the effect of free convection on heat transfer. Thus, allowing to neglect it when solving the equations of similarity.

Geometric criterion responsible for the geometric region of convective heat transfer and allowing to take into account the effect of the film-forming element on the hydrodynamics of the film flow. Therefore, it is advisable to determine it taking into account the length of the edge of the blade element and the reflective heated plate $(c)$ to the length of the circle of the working chamber $\pi D$, taking into account the number of film-forming elements $z$. It is also necessary to take into account the relative height $h / \delta$ to take into account the bevel angle of the blade and the value of its immersion in the experimental raw material, therefore, the criterion will be as follows:

$$
P_{G}=\frac{c z}{\pi D} \cdot \frac{h}{\delta}
$$

In this case, the calculation of the coefficient of heat transfer from the working surface to the raw material in a rotary film evaporator with heating film-forming elements is reduced to the analysis of physical processes, and therefore the following criterion equation can be recommended:

$$
N u=A \operatorname{Re}_{c}^{n_{1}} \operatorname{Pr}_{r}^{n_{2}}\left(\frac{v_{\text {boil }}}{v}\right)^{n_{3}} \cdot\left(\frac{v_{\text {film }}}{v}\right)^{n_{4}} \cdot P_{G}^{n_{5}} .
$$

Mathematical processing of the criterion equation, taking into account the previously selected experimental data in the MathCad package, confirms that the obtained criterion is statistically significant. Consequently, the obtained criterion equation for determining the heat transfer coefficient from the working surface of the rotary film evaporator and the improved film-forming element to the experimental raw material (blended fruit and berry puree) will have the following form:

$$
N u=5.842 \cdot \operatorname{Re}_{C}^{0.051} \operatorname{Pr}_{r}^{0.246}\left(\frac{v_{\text {boil }}}{v}\right)^{0.200}\left(\frac{v_{f i l m}}{v}\right)^{0.273} \Pi_{G}^{0.0481},
$$

The relative error of the obtained criterion equation is $0.95 \%$, and equation 13 is reliable within the following boundaries of scientific and practical approbation use: $\operatorname{Re}_{\text {center }} \cdot 10^{3}=85.2 \ldots 120.2$; $v_{\text {film }} \cdot 10^{3}=3.050 \ldots 5.295 ; v_{\text {film }} \cdot 10^{3}=4.340 \ldots 12.120$.

To confirm the effectiveness of the proposed engineering solutions regarding the expediency of using a film-forming 
element with a reflective surface heated by FFRREH in rotary film evaporators, a comparative analysis of the main research parameters with a traditional vacuum evaporator was carried out (Table 1). The thermal design of the improved rotary film evaporator was performed using a valid equation (13). The data determined as a result of the calculation fully meet the limiting conditions within the limits of scientific and practical approbation use. The initial data for calculating the rotary film evaporator is the productivity $-100 \mathrm{~kg} / \mathrm{h}$, the diameter of the apparatus body $-0.2 \mathrm{~m}$.

Table 1

Characteristics of a rotary film apparatus in comparison with a vacuum evaporation apparatus

\begin{tabular}{|c|c|c|}
\hline Indicator & $\begin{array}{l}\text { Vacuum evaporating } \\
\text { apparatus (MZS-320) }\end{array}$ & $\begin{array}{l}\text { Rotary film apparatus } \\
\text { (RFA) }\end{array}$ \\
\hline $\begin{array}{l}\text { Apparatus } \\
\text { weight }\end{array}$ & $m^{*}=1520 \mathrm{~kg}$ & $m=43 \mathrm{~kg}$ \\
\hline $\begin{array}{l}\text { For heating } \\
\text { and boiling } \\
\text { the product }\end{array}$ & $\begin{array}{c}Q_{p r}=m c\left(t_{k}-t_{\mathrm{n}}\right)+r m_{\text {cond }}= \\
=1,500 \cdot 3.7 \cdot(65-50)+ \\
+2,350 \cdot 600=1,493,250 \mathrm{~kJ}\end{array}$ & $\begin{array}{c}Q_{p r}=G c\left(t_{k}-t_{\mathrm{n}}\right)+r G_{\text {cond }}= \\
=3,700 \times 0.028(65-50)+ \\
+2,350 \times 10^{3} \times \\
\times 0.0052=13,540 \mathrm{~J} / \mathrm{s}\end{array}$ \\
\hline $\begin{array}{c}\text { Heat ex- } \\
\text { change surface }\end{array}$ & $3.7 \mathrm{~m}^{2}$ & $0.75 \mathrm{~m}^{2}$ \\
\hline $\begin{array}{l}\text { Duration of } \\
\text { processing }\end{array}$ & $\begin{array}{c}\mathrm{T}_{\mathrm{VEA}}=Q / F \cdot k \cdot \Delta t= \\
=1,510,530 / 3.7 \cdot 1,454 \cdot 78= \\
=3,600 \mathrm{~s}\end{array}$ & $\begin{array}{l}\mathrm{T}_{\mathrm{RFA}}=L_{a n} / \mathrm{v}_{\text {film }}= \\
=1.2 / 0.005=200 \mathrm{~s}\end{array}$ \\
\hline $\begin{array}{c}\text { Specific metal } \\
\text { consumption }\end{array}$ & $\begin{array}{c}M=m^{*} / F^{*}=1,520 / 3.7= \\
=410 \mathrm{~kg} / \mathrm{m}^{2}\end{array}$ & $\begin{array}{c}M=m / F= \\
=43 / 0.75=57 \mathrm{~kg} / \mathrm{m}^{2}\end{array}$ \\
\hline
\end{tabular}

Note: * comparative data of the basic design of the M3C-320, taken from the literature [18].

Specific metal consumption in RFA with a film-forming element having a reflective surface is $57 \mathrm{~kg} / \mathrm{m}^{2}$, compared to traditional vacuum evaporators for canning production $\left(410 \mathrm{~kg} / \mathrm{m}^{2}\right)$, which is 7.1 times less. At the same time, the duration of the temperature effect on the raw material is significantly reduced: a rotary film evaporator $-200 \mathrm{~s}$ and $3600 \mathrm{~s}$ in a traditional VEA.

\section{Discussion of the results obtained for the concentration of organic puree in an improved rotary film evaporator}

Experimental and practical studies confirm the effectiveness of using an improved rotary film evaporator with the proposed film-forming element having a reflective heated surface (Fig. 1). The proposed constructive solution is aimed at stabilizing the hydraulic movement of the cut wave flow due to the reflecting surface of a certain geometric shape, which will allow the cut raw material to be forcedly directed to the heating surface (Fig. 1, b,c). And due to the autonomous playing area of the reflective surface, an additional temperature effect is realized in the conditions of movement of the particles of the raw material after cutting.

A generalized criterion equation has been formed to determine the heat transfer coefficient of a rotary film evaporator with the proposed film-forming element with a reflective heated surface to calculate the heat transfer coefficient from the working surface to the raw material (13). Practical use of the proposed solutions due to additional autonomous heating of the reflecting surface of FFRREH and taking into account this parameter in the criterion equation provides an increase in the heat exchange surface of the RFA up to $0.75 \mathrm{~m}^{2}$ (Table 1). In this case, the specific metal consumption in a rotary film evaporator with a film-forming element reflecting the surface is $57 \mathrm{~kg} / \mathrm{m}^{2}$. This is 7.1 times less than the traditional vacuum evaporator $410 \mathrm{~kg} / \mathrm{m}^{2}$ (Table 1). It also provides a decrease in the duration of the temperature effect on the raw material: rotary film evaporator $-200 \mathrm{~s}$ and 3,600 $\mathrm{s}$ in traditional RFA (Table 1). Thus, ensuring the difference between the proposed engineering and design solutions from analogs in which concentration is implemented using intermediate coolants with an artificial decrease in the efficiency of the process as a whole [19].

One of the limitations when concentrating organic purees, dairy products, etc. is the stabilization of the temperature of the working surface depending on the specific load of the apparatus, which requires the use of regulation of the volume of raw materials supplied for boiling. Further research can be aimed at determining the influence of the speed of revolutions of the improved film-forming element and the hydrodynamic and heat and mass transfer models of the concentration of various nutrients.

\section{Conclusions}

1. A model of a rotary film evaporator with the proposed film-forming element is improved, which has a reflective heated surface. Such a solution is proposed to stabilize the hydraulic motion of the cut wave flow due to a reflective surface of a geometric shape, which will allow the cut raw material to be forcibly directed to the heating surface. In addition, an important factor, in addition to stabilizing the wave motion, is to provide heating of the reflecting surface area for an additional temperature effect under conditions of movement of raw material particles after cutting.

2 . As a result of the analysis of the experimental and theoretical parameters of the heat transfer process, the criterion equation for the heat transfer coefficient of a rotary film evaporator with the proposed film-forming element having a reflective heated surface for calculating the heat transfer coefficient from the working surface to the raw material is substantiated. The calculation of the rotary-film evaporator using the criterial equation was carried out and the useful heat exchange surface of the RFA is obtained $-0.75 \mathrm{~m}^{2}$. It is found that the specific metal consumption in a rotary film evaporator with a film-forming element having a reflective surface is $57 \mathrm{~kg} / \mathrm{m}^{2}$, compared with a traditional vacuum evaporator $410 \mathrm{~kg} / \mathrm{m}^{2}$, which is 7.1 times less. At the same time, the duration of the temperature effect on the raw material is significantly reduced: a rotary film evaporator $-200 \mathrm{~s}$ and $3600 \mathrm{~s}$ in a traditional VEA.

\section{Acknowledgments}

The work is carried out on the state budget theme No. 1-21 BU "Development of technological processes and low-temperature equipment for the production of multifunctional semi-finished products and confectionery products using organic raw materials" under the guidance of Assoc. Prof. Andrii Zagorulko. 


\section{References}

1. Shkuratov, O. I., Drebot, O. I., Chudovska, V. A. et. al. (2014). Kontseptsiya rozvytku orhanichnoho zemlerobstva v Ukraini do 2020 roku. Kyiv: TOV «Ekoinvestkom», 16 .

2. Terpou, A., Papadaki, A., Bosnea, L., Kanellaki, M., Kopsahelis, N. (2019). Novel frozen yogurt production fortified with sea buckthorn berries and probiotics. LWT, 105, 242-249. doi: https://doi.org/10.1016/j.lwt.2019.02.024

3. Pap, N., Fidelis, M., Azevedo, L., do Carmo, M. A. V., Wang, D., Mocan, A. et. al. (2021). Berry polyphenols and human health: evidence of antioxidant, anti-inflammatory, microbiota modulation, and cell-protecting effects. Current Opinion in Food Science, 42, 167-186. doi: https://doi.org/10.1016/j.cofs.2021.06.003

4. Misra, N. N., Koubaa, M., Roohinejad, S., Juliano, P., Alpas, H., Inácio, R. S. et. al. (2017). Landmarks in the historical development of twenty first century food processing technologies. Food Research International, 97, 318-339. doi: https://doi.org/10.1016/ j.foodres.2017.05.001

5. Boesveldt, S., Bobowski, N., McCrickerd, K., Maître, I., Sulmont-Rossé, C., Forde, C. G. (2018). The changing role of the senses in food choice and food intake across the lifespan. Food Quality and Preference, 68, 80-89. doi: https://doi.org/10.1016/ j.foodqual.2018.02.004

6. Silveira, A. C. P. (2015). Thermodynamic and hydrodynamic characterization of the vacuum evaporation process during concentration of dairy products in a falling film evaporator. Food and Nutrition. Agrocampus Ouest. Available at: https:// tel.archives-ouvertes.fr/tel-01342521/document

7. Crespí-Llorens, D., Vicente, P., Viedma, A. (2018). Experimental study of heat transfer to non-Newtonian fluids inside a scraped surface heat exchanger using a generalization method. International Journal of Heat and Mass Transfer, 118, 75-87. doi: https:// doi.org/10.1016/j.ijheatmasstransfer.2017.10.115

8. Cokgezme, O. F., Sabanci, S., Cevik, M., Yildiz, H., Icier, F. (2017). Performance analyses for evaporation of pomegranate juice in ohmic heating assisted vacuum system. Journal of Food Engineering, 207, 1-9. doi: https://doi.org/10.1016/j.jfoodeng.2017.03.015

9. Zahorulko, A., Zagorulko, A., Yancheva, M., Ponomarenko, N., Tesliuk, H., Silchenko, E. et. al. (2020). Increasing the efficiency of heat and mass exchange in an improved rotary film evaporator for concentration of fruit-and-berry puree. Eastern-European Journal of Enterprise Technologies, 6 (8 (108)), 32-38. doi: https://doi.org/10.15587/1729-4061.2020.218695

10. Mykhailov, V., Zahorulko, A., Zagorulko, A., Liashenko, B., Dudnyk, S. (2021). Method for producing fruit paste using innovative equipment. Acta Innovations, 39, 15-21. doi: https://doi.org/10.32933/actainnovations.39.2

11. Zahorulko, A., Zagorulko, A., Yancheva, M., Serik, M., Sabadash, S., Savchenko-Pererva, M. (2019). Development of the plant for low-temperature treatment of meat products using ir-radiation. Eastern-European Journal of Enterprise Technologies, 1 (11 (97)), 17-22. doi: https://doi.org/10.15587/1729-4061.2019.154950

12. Imran, A., Rana, M. A., Siddiqui, A. M. (2018). Study of a Eyring-Powell Fluid in a Scraped Surface Heat Exchanger. International Journal of Applied and Computational Mathematics, 4 (1). doi: https://doi.org/10.1007/s40819-017-0436-z

13. Martínez, D. S., Solano, J. P., Vicente, P. G., Viedma, A. (2019). Flow pattern analysis in a rotating scraped surface plate heat exchanger. Applied Thermal Engineering, 160, 113795. doi: https://doi.org/10.1016/j.applthermaleng.2019.113795

14. Błasiak, P., Pietrowicz, S. (2019). A numerical study on heat transfer enhancement via mechanical aids. International Journal of Heat and Mass Transfer, 140, 203-215. doi: https://doi.org/10.1016/j.ijheatmasstransfer.2019.05.116

15. Acosta, C. A., Yanes, D., Bhalla, A., Guo, R., Finol, E. A., Frank, J. I. (2020). Numerical and experimental study of the glass-transition temperature of a non-Newtonian fluid in a dynamic scraped surface heat exchanger. International Journal of Heat and Mass Transfer, 152, 119525. doi: https://doi.org/10.1016/j.ijheatmasstransfer.2020.119525

16. Cherevko, O., Mikhaylov, V., Zahorulko, A., Zagorulko, A., Gordienko, I. (2021). Development of a thermal-radiation single-drum roll dryer for concentrated food stuff. Eastern-European Journal of Enterprise Technologies, 1 (11 (109)), 25-32. doi: https:// doi.org/10.15587/1729-4061.2021.224990

17. Zahorulko, A. M.,Zahorulko, O. Ye. (2016). Pat. No. 108041 UA. Hnuchkyi plivkovyi rezystyvnyi elektronahrivach vyprominiuiuchoho typu. No. u201600827; declareted: 02.20.2016; published: 24.06.2016, Bul. No. 12. Available at: https://uapatents.com/5-108041gnuchkijj-plivkovijj-rezistivnijj-elektronagrivach-viprominyuyuchogo-tipu.html

18. Vakuum-vyparnoy apparat MZS-320. Available at: https://www.mzko.com.ua/2015-08-03-00-59-07/vacuum-vyparnoy-apparat.html

19. Cherevko, A., Mayak, O., Kostenko, S., A. Sardarov (2019). Experimental and simulation modeling of the heat exchanche process while boiling vegetable juice. Prohresyvni tekhnika ta tekhnolohiyi kharchovykh vyrobnytstv restorannoho hospodarstva i torhivli, 1, 75-85. Available at: http://nbuv.gov.ua/UJRN/Pt_2019_1_9 